
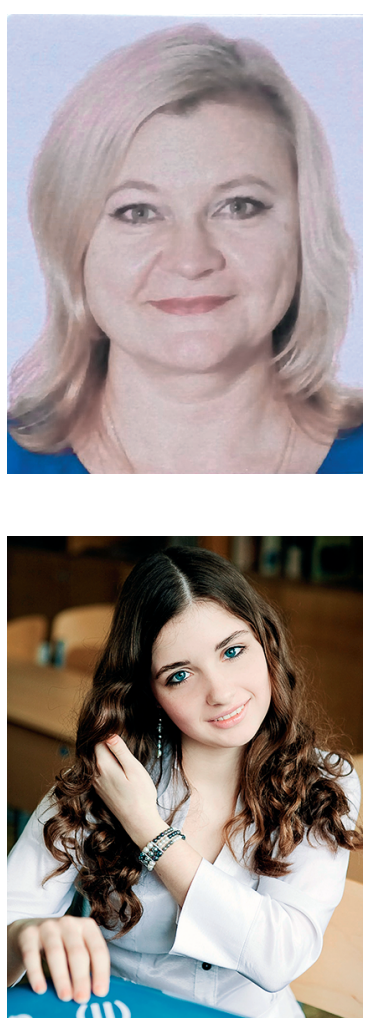

\section{Нелюбова Наталия Юрьевна}

Кандидат филологических наук, доцент

Кафедра иностранных языков филологического фракультета, Российский университет дружбы народов, 117198,

Российская Федерация, г. Москва, ул. Миклухо-Маклая, д.6, e-mail: nat.nelubova@mail.ru

\section{Natalia U. Nelubova}

$\mathrm{PhD}$ in Philology, Associate Professor

Foreign Languages Department of the Philological Faculty, RUDN University, 6, Miklukho-Maklaya Str., 117198, Moscow, Russian Federation, e-mail: nat.nelubova@mail.ru

\section{Гурова Анастасия Валерьевна}

Студент 2-ого курса магистратуры

Кафедра иностранных языков филологического факультета, Российский университет дружбы народов, 117198,

Российская Федерация, г. Москва, ул. Миклухо-Маклая, д.6, e-mail: gurovaanastassya@gmail.com

\section{Anastasiia V. Gurova}

2nd year master degree student

Foreign Languages Department of the Philological Faculty, RUDN University, 6, Miklukho-Maklaya Str., 117198, Moscow, Russian Federation, e-mail: gurovaanastassya@gmail.com

\title{
РОЛЬ ЛИНГВОКУЛЬТУРНОГО ФАКТОРА ПРИ ПЕРЕВОДЕ ФРАНЦУЗСКОЙ И РУССКОЙ ДЕЛОВОЙ ИНТЕРНЕТ-ПЕРЕПИСКИ
}

\footnotetext{
Аннотация. В данной статье затрагиваются проблемы перевода деловой интернет-переписки с французского языка на русский с учетом лингвокультурного аспекта. Нами были рассмотрены основные теоретические положения, связанные с данной проблематикой, и представлены результаты проведенного исследования. Проведенный анализ показал, что наличие большого количества фрормул вежливости во фрранцузских деловых письмах придает им особую тональность, в то время как русское письмо также имеет свою тональность, но с использованием более простых формул вежливости. Было выявлено, что в деловом письме может присутствовать широкозначная лексика, которая нуждается в особом внимании переводчика, так как он должен подобрать правильный эквивалент для того, чтобы его перевод был адекватным и понятным адресанту. Обращается внимание на то, что существует три вида эквивалентности при переводе: фрормальный (при переводе используются средства языка перевода, аналогичные средствам языка оригинала),
} 
смысловой (переводится значение на язык перевода, отличными средствами от языка оригинала) и ситуативный (выражения, касающиеся одной ситуации, переводятся различными языковыми средствами), и, соответственно, при анализе писем официально-делового стиля выделяется три вида клише: клише-кальки, смысловые клише и ситуативные клише. В качестве материала для анализа нами были взяты деловые письма французских компаний и приведены примеры перевода французских деловых писем на русский язык, предложен анализ текстов писем оригинала и перевода и сделан вывод о том, что лингвокультурный аспект в переводе деловых писем, прежде всего, предполагает правильное употребление переводчиком фрормул вежливости и клишированной лексики.

Ключевые слова. Лингвокультурология, лингвокультурный аспект, особенности перевода, официально-деловая переписка, фрранцузское деловое письмо, русское деловое письмо.

Информация о статье. Дата поступления 26 октября 2017 г.; дата принятия к печати 22 января 2018 г.; дата онлайн-размещения 05 февраля 2018 г.

\title{
THE ROLE OF THE LINGUOCULTURAL FACTOR IN TRANSLATION OF FRENCH AND RUSSIAN ONLINE BUSINESS CORRESPONDENCE
}

\begin{abstract}
This article is devoted to the problem of translating online business correspondence from French into Russian taking into account the linguocultural aspect. The authors consider the main theoretical grounds related to the problem and present the findings of their study in the article. The research shows that French business letters contain more politeness formulas compared with Russian business letters and this feature creates a particular tone of the French letters. The Russian letters, in their turn, also have a special tone, but it is achieved by using more simple politeness formulas. The article identifies a business letter can contain multiple meaning words, the translator needs to pay special attention to, as they need to find a good equivalent in the target language to ensure their translation is adequate and understandable to the reader. It is important to highlight that there are three types of translation equivalence: formal (translation into the target language by linguistic means similar to ones in the source language), semantic (translation of the meaning of the text using different linguistic means) and situational (translation of expressions describing the same situation using different linguistic means). Therefore, a translator has to differ between three types of clichés: literal clichés, semantic clichés and situational clichés. As an input for the research the authors use business letters of French companies and offer their translation from French into Russian. Then they analyse texts of the letters in the source language and in the target language and conclude, that the lingucultural aspect involves, first of all, correct translation of politeness formulas and clichés.
\end{abstract}

Keywords. Linguistic culturology, linguocultural aspect, translation specifics, business correspondence, French business letter, Russian business letter.

Article info. Received October 26, 2017; accepted January 22, 2018; available online February 05, 2018. 


\section{Введение}

В настоящее время все больше проявляется тенденция к дальнейшему развитию мира деловых отношений. Появляются новые средства коммуникации, и новейшие технологии заменяют привычные вещи. Эти изменения коснулись также и мира деловых отношений и деловой коммуникации - сегодня ни одна компания не может обойтись без электронной почты, так как она гарантирует мгновенную доставку делового письма получателю в любую точку мира. В данной статье будут рассматрены особенности деловой переписки между российскими и французскими компаниями, а в частности - особенности перевода деловой интернет-переписки между ними.

При создании любого речевого материала необходимо наличие трех основных компонентов: темы произведения; ситуации, в рамках которой происходит коммуникативный акт и участников коммуникативного акта, которые владеют знаниями не только лингвистическими, но и экстралингвистическими. Соответственно, невозможно достичь адекватности перевода без учета внеязыковых факторов. Поскольку определенные экстралингвистические фракторы в культурах языка оригинала (ЯО) и языка перевода (ЯП) могут отличаться друг от друга или отсутствовать в одной из культур, переводчик должен быть достаточно компетентен для того, чтобы адекватно передать содержание текста ЯО в понятной для читателя форме [1].

Таким образом, наше внимание привлекли особенности перевода французских офрициально-деловых писем на русский язык с учетом лингвокультурологического аспекта, а также влияние культуры народа на выбор языковых средств при переводе текста официально-делового письма.

Теоретической базой настоящего исследования послужили работы таких российских и зарубежных ученых, как Балли Ш., Бахтин М. М.,Виноградов В. С., Воробьев В. В., Гаврилова К. С., Галеева Н. Л., Граудина Л. К., Гумбольдт В., Зализняк А. А., Земская Е. А., Иванова С. В., Иссерлин Е. М., Карасик В. И., Колтунова М. В., Коняева Е. А., Маслова В. А., Микаелян И. Л., Морен М. К., Попова Г. Ф., Розенталь Д. Э., Савченко Т. В., Тетеревникова Н. Н., Трофимова Г. Н., Чернышева 3. 3., Шаклеин В. М., Ширяев Е. Н.

\section{Особенности лингвокультурологического анализа текстов}

В настоящее время лингвистический анализ имеет целью не только выявление особенностей языковых единиц, но и установление связи между языком и человеком, его культурой, менталитетом. Таким образом, в современной лингвистике можно выделить идею антропоцентричности. Она ставит человека на первое место, а язык является его главной составляющей. Разум и интеллект человека не мыслится вне языка. При помощи различных языковых средств человек думает, излагает свои мысли в устной и письменной фрормах [2; 3].

Исходя из вышесказанного можно предположить, что лингвокультурология представляет собой продукт антропоцентрической идеи, так как она направлена на изучение культурного фактора в языке и языково- 
го фактора в человеке. Она является одним из основных направлений современной лингвистики [2].

При лингвокультурологическом анализе возникает проблема выбора единицы анализа. Исследователи предлагают множество единиц, что вызвано многочисленными подходами к осуществлению лингвокультурологического анализа. В. В. Воробьёв ставит в центр изучения проблемы взаимосвязи языка, личности и культуры и выделяет такую единицу исследования, как архикультурему, которая является лексической единицей, несущей признаки культуры. Похожей точки зрения придерживается Н. Г. Брагина, которая выделяет в качестве единицы исследования культурно маркированные, стабильные выражения и словосочетания, принадлежащие сорере нематериальной культуры: абстрактные существительные, обозначающие мир, чувства, мысли, эмоции человека [4].

Кроме того, если исследование основано на сравнительном анализе, то в качестве единицы может быть выбрана культурологическая лакуна, которая показывает расхождение, несоответствие локальных культур [4]. Согласно Г. В. Быковой, лакуна - это концепт, который не имеет средств языкового выражения в системе языка перевода. 3. Д. Попова и И. А. Стернин определяют понятие «лакуны» как «отсутствие в одном из языков сопоставляемых между собой наименований того или иного понятия, имеющегося в другом языке» [5].

\section{Лингвокультурологический анализ в переводе}

Перевод с использованием лингвокультурологического анализа мо- жет быть скрытым и представлять собой заимствование культур, сюжетов, тем, мотивов и тому подобное. Французский социолог и философ А. Лефевр, стоящий у истоков лингвокультурологического аспекта в западных переводческих исследованиях, считал, что изначально существовало два вида перевода:

- перевод, являющийся языковой деятельностью, которая заключается в простом обмене информацией;

- перевод, который представляет собой перенос особенностей одной культуры в другую, без использования эквивалентного перевода.

Итак, при переводе текстов, которые представляют культурный капитал той или иной страны, существует две основные переводческие тенденции. Первая заключается в том, что принимающая культура максимально адаптирует оригинальный текст к своим нормам и традициям. Вторая тенденция представляет собой перенос особенностей оригинального текста и культуры оригинала в принимающую сторону, то есть перевод осуществляется с сохранением всех особенностей языка оригинала, причем это происходит осознанно [6].

Кроме того, перевод может иметь разные цели и задачи и быть ориентирован на культуру оригинала или на культуру перевода. Именно этим объясняется тот фракт, что не возникает вопроса о необходимости верности оригиналу, точности или эквивалентности. На один оригинал переводов может быть несколько, так как каждый переводчик сам выбирает (или для него ставят) задачи и цели перевода. Кроме того, перевод может устаревать, так как язык и культура постоянно находятся в процессе развития [6]. 
Таким образом, лингвокультурный аспект перевода представляет собой рассмотрение реалий, которые существуют в двух культурах (в культуре языка оригинала и в культуре языка перевода). В. С. Виноградов определяет термин «реалия» как фоновую информацию, в которой может содержаться история, культура, государственное устройство данной страны и так далее. Также термин «реалия» понимается не только как факты или события, но как слова или словосочетания, их обозначающие [7].

Лингвокультурологический подход к переводу текстов является особенно актуальным при переводе деловой корреспонденции. При переводе данного вида текстов необходимо учитывать культурные особенности страны, на язык которой осуществляется перевод, поскольку малейшее недопонимание в данной области может привести к разрыву деловых отношений между партнерами, компаниями и даже государствами. Прежде чем переводить тексты деловой корреспонденции, необходимо изучить особенности официально-делового стиля речи как в языке оригинала, так и в языке перевода.

\section{Особенности официально- делового стиля речи французского и русского языков}

Стиль представляет собой разновидность языка, которая отражает в себе черты определенной стороны общественной жизни: быта, профессионального общения, науки, рекламы, художественной литературы. Стиль является неотъемлемой частью различных композиционных единств, а также элементом жанрового единства фразы или высказывания. Таким образом, стиль характеризуется выбором фразеологических, грамматических и словарных фрорм языка и отражает цели и условия определенной области высказывания. Каждый из стилей речи реализуется в определенных формах речи, то есть жанрах. В теории текста жанр «объективный экстралингвистический фрактор текстообразования». М. М. Бахтин понимал под термином «жанр» достаточно устойчивые типы высказываний определенной тематики, композиции и стилистики [8].

Л. К. Граудина и Е. Н. Ширяев предлагают понятие «функциональная разновидность языка», что можно объяснить большим разнообразием областей общения, в которых наблюдаются языковые различия. Они считают, что применять к этим областям один общий термин «стиль» было бы не достаточно [9].

В данной работе мы придерживаемся определения, данного М. М. Бахтиным, согласно которому стиль и жанр понимаются как два неразрывно связанных между собой элемента текста, которые определяются своеобразием области общения.

Официально-деловой стиль является одним из функциональных стилей литературного языка, который используется в таких областях, как правовая, административная, коммерческая деятельность. Основной формой употребления является письменная, но также имеет место быть устная форма, характерная для заседаний, собраний, переговоров. Официально-деловому стилю отводится важная роль в формировании деловой корреспонденции [8]. 
Главным признаком официально-делового текста является точность изложения и отсутствие иного толкования высказывания, что является причиной наличия таких признаков, как особая тональность текста, шаблонность средств выражения. Кроме того, неотъемлемыми признаками текста официально-делового стиля являются строгость, четкость, объективность и, можно даже сказать, безличность изложения. Также ему присуще отсутствие эмоциональных субъективных оценок высказывания [10].

Кроме того, важной чертой делового стиля является стандартизация и унификация языковых средств. Они характерны для лексического и грамматического уровней языка, что образует устойчивый речевой стереотип. Данные характеристики официальноделового стиля помогают облегить читателю понимание сути и проблемы текста, так как он сразу может выделить ключевые моменты и быстрее вникнуть в тему сообщения [11].

Поскольку в данной работе речь идет об особенностях перевода французской деловой корреспонденции на русский язык, необходимо выявить характерные черты французского и русского официально-делового стиля и французской и русской деловой переписки.

Главной особенностью французской и русской деловой переписки является точность и четкость изложения, а также отсутствие языковых форм, выражающих эмоции. В деловой корреспонденции почти полностью исключается произвольное толкование вопроса или проблемы. Необходимо придерживаться нейтрального повествования при изложении сути письма, запрещается употребление грубых выражений, которые могут оскорбить каким-либо образом адресата. Можно выделить следующие отличительные черты, которым должен отвечать качественный перевод деловой переписки:

- точность - все, что указано в тексте оригинала, должно присутствовать в тексте перевода;

- сжатость - в переводе необходимо кратко излагать информацию;

- ясность - несмотря на сжатость текста, нужно сохранять лексику, которая обязательна для его полного понимания;

- литературность - текст должен соответствовать литературным нормам языка перевода и не должен содержать синтаксических конструкций языка оригинала [12, с. 103; 13].

Кроме того, необходимо упомянуть о лексических различиях деловой переписки на французском и русском языках. Важной частью делового письма на французском языке является наличие большого количества формул вежливости по сравнению с письмом на русском языке, что придает деловому письму особую тональность, устанавливающуюся между адресатом и адресантом [13]. Во французских деловых письмах можно встретить следующие формулы вежливости: (Cher/chère) Monsieur/Madame, sincèrement à vous, cordialement, veuillez agreér (cher/chère) Monsieur/ Madame mes salutations cordiales (sentiments distingués...) и т. п. В русском письме также присутствуют формулы вежливости, но в более простой форме: Уважаемый/ая..., Надеемся на дальнейшее сотрудничество..., С уважением и т. п.

В текстах деловой переписки присутствует большое количество 
широкозначной лексики [11]. По определению П. Ньюмарка, широкозначная лексика - это сложная проблема переводчиков, которая заключается в том, что широкозначная лексика имеет большое количество контекстуальных и словарных соответствий, из которых бывает достаточно трудно выбрать наиболее подходящий вариант [13]. Примером подобной лексики может послужить французское слово «directeur», которое будет переводиться по-разному в зависимости от контекста: le directeur général - генеральный $\partial u$ ректор; le directeur de production начальник производственного оmдела; le directeur de la promotion директор по маркетингу и так далеe.

\section{Перевод официально-деловой корреспонденции}

При переводе данного вида лексики необходимо использовать окказиональные соответствия. Согласно толковому словарю С. И. Ожегова термин «окказиональный» определяется как случайный, единичный, а «окказиональные слова» как индивидуальные неологизмы [14]. Для выбора более подходящего соответствия необходимо обращаться к лингвистическому и ситуативному контексту [15]. Например, перевод французского слова "chef» на русский язык будет зависеть от ситуации, в которой оно употребляется: chef d'Etat - глава государства, президент; chef du département глава департамента, начальник отдела; chef d'entreprise - pyководитель предприятия, предприниматель; chef des ventes менеджер по продажам и так далее.
Также деловые документы обычно являются четко стандартизированными, что приводит к тому, что при переводе не всегда удается найти адекватный эквивалент в языке перевода, из-за чего приходится прибегать к дословному переводу. Данный тип перевода необходим для того, чтобы избежать неверного толкования того или иного термина или высказывания, поскольку в противном случае это может привести к осложнению отношений, вплоть до международного скандала.

Кроме того, при переводе текстов деловой корреспонденции необходимо знать правила употребления клишированной лексики в деловых письмах во фрранцузском и русском языках, а также владеть навыками делового этикета двух данных языков $[16 ; 17]$.

Перевод единиц одного языка на другой неразрывно связан с понятием эквивалентности. Существует несколько подходов к определению эквивалентности. Один из таких подходов предложили В. Г. Гак и Ю. И. Львин. Они различают три вида эквивалентности: формальный, смысловой и ситуативный.

1. Под формальным эквивалентом понимается перевод единиц одного языка аналогичными средствами другого языка.

2. Под смысловым эквивалентом предполагается перевод одного и того же значения в обоих языках различными языковыми средствами.

3. Под ситуативным эквивалентом понимают перевод выражений, которые описывают одну ситуацию, при помощи различных языковых средств и элементарных значений [18]. 
При анализе клише официальноделового языка выделяют три вида клише, которые соответствуют перечисленным выше видам эквивалентности: клише-кальки, смысловые клише и ситуативные клише.

1. Клише-кальки помогают достигнуть формальной эквивалентности при переводе за счет употребления аналогичных языковых средств во французском и русском языках. Клише-кальки являются эквивалентными и по смыслу, и по форме. (Dans l'attente de votre accord... - $B$ ожидании вашего согласия...).

2. Смысловые клише предполагают использование различных языковых средств для выражения одного и того же значения. При переводе данного вида клише предпринимаются различные трансформации на семантическом уровне. (En référence à notre conversation téléphonique... - Я ссылаюсь на наш телефронный разговор...).

3. Ситуационные клише обязательно связаны с какой-то определенной ситуацией и являются едиными законченными высказываниями. Для установления отношений эквивалентности переводчик должен знать ситуационные клише во французском и русском языках, поскольку французские клише в больше степени направлены на соблюдение установленных этикетных норм и правил, в то время как в русском языке вычурно вежливая фраза может произвести обратный эффект - адресат может рассмотреть такую фрразу как насмешку. Так как семантическая информация двух аналогичных ситуационных клише в рассматриваемых языках различается, то эквивалентность будет достигаться не на грамматическом и лексическом уров- нях, а на уровне смыслов. (Veuillez agréer, Monsieur D., l'expression de mes sentiments distingués. - С уважением.) [18].

\section{Примеры перевода деловых писем и их анализ}

В качестве материала для анализа нами были взяты 50 деловых писем франко-российских компаний, а также 25 мотивационных писем, которые были переведены с французского языка на русский и с русского языка на фрранцузский с учетом лингвокультурологического аспекта. Имена, адреса, а также некоторые данные в письмах, приведенных ниже, были изменены в целях соблюдения конфиденциальности информации.

Рассмотрим пример официально-делового письма на французском языке и представим его перевод на русский язык, выполненный с учетом всех вышеперечисленных особенностей:

Comité central

d'entreprise

de Leroy-Merlin

25, rue du Château-Landon

75010 Paris

France

Tél.: 0193922332

Paris, le 26 février 2010

Monsieur Nicolay V. Ivanov

Directeur du magasin

5 Tverskaya

105010 Moscou

Russie

Monsieur le Directeur,

Comme j'ai pu vous le préciser lors de notre dernière rencontre, vous pouvez compter sur l'aide et l'appui de notre Comité Central d'Entreprise dans 
vos démarches afin de mener à bien votre projet d'implanter un nouveau type des papiers de tenture.

Pour celui-ci, les soutiens que votre magasin a obtenus depuis notre échange s'avèrent précieux. Ainsi, à vous lire, Madame Idroc, Présidente également de notre Comité, n’a émis que des réserves liées à l'état de ce type de matériel. Une remarque, à ce stade, qui m'apparaît fondée. En effet, l'incertitude demeure quant à sa conservation et notamment sa durabilité.

M'engageant à vous tenir informé et souhaitant avoir répondu à votre attente, je vous pris de croire, Monsieur le Secrétaire, à l'assurance de mes cordiales et amicales salutations.

Sylvain Braire Secrétaire d'Entreprise

Ниже приведен перевод данного письма на русский язык и рассмотрены особенности, характерные для данного перевода:

\section{Дирекция}

Предприятия Леруа-Мерлен

Франция

75010 Париж,

ул. Шато-Ландон, 25

тел.: 0193922332

Париж, 26 февраля 2010 г.

Директору магазина

Г-ну Н. В. Иванову

Россия

105010 Москва, ул. Тверская, 5

Уважаемый г-н Иванов,

Как я отметил во время нашей последней встречи, Вы можете рассчитывать на помощь и поддержку со стороны Дирекции нашего пред- приятия в проведении мероприятий, касающихся успешного завершения проекта по продвижению на рынке нового вида обоев.

Поддержка, которую Ваш магазин получал с начала нашего сотрудничества, требует больших затрат. Кроме того, у г-жи Идрок, которая также входит в состав Дирекции, имеется ряд замечаний, касающихся материала, из которого изготовлены обои. На данном этапе мне показалось важным одно из них, касающееся сомнений по поводу условий хранения материала и его долговечности.

Обязуюсь держать Вас в курсе всех изменений и надеюсь, что Ваши ожидания оправдаются.

С уважением.

\section{Сильвэн Брэр}

Секретарь

Прежде всего, необходимо отметить, что фрранцузское письмо написано в официально-деловом стиле с употреблением различных фрраз-клише: Comme j'ai pu vous le préciser... vous pouvez compter sur l'aide et l'appui de ... Ainsi, à vous lire... M'engageant à vous tenir informé... je vous prie de croire, Monsieur le Secrétaire, à l'assurance de mes cordiales et amicales salutations.

Кроме того, можно наблюдать употребление широкозначной лексики: directeur du magasin ректор магазина, comité central d'entreprise - дирекция предприятия, implanter un nouveau type... продвигать на рынок новый вид..., type des papier de tenture/ de matériel - вид обоев.

При переводе данного письма с французского языка на русский мы учли особенности восприятия тек- 
ста письма русским получателем, то есть лингвокультурологический аспект. Прежде всего, данный аспект касается перевода фраз-клише. В данном переводе нами были использованны следующие виды клише:

- клише-кальки, которые совпадают с оригиналом и по форме, и по содержанию: vous pouvez compter sur l'aide et l'appui de... - Вы можете рассчитывать на помощь и поддержку....;

- смысловые клише, которые используют различные языковые средства для выражения одного значения: Comme j'ai pu vous le préciser... - Как я отметил...; Ainsi, à vous lire... - Кроме того...; M'engageant à vous tenir informé... Обязуюсь сообщать Вам о...;

- ситуационные клише, которые являются законченными высказываниями и обычно не совпадают в разных языках: je vous pris de croire, Monsieur le Secrétaire, à l'assurance de mes cordiales et amicales salutations. - C уважением.

Рассмотрим пример мотивационного письма на французском языке для получения работы в крупной сети отелей в России:

Marie Fabuse

31, rue d'Etoile

175011 Bordeau

France

Tél.: 0132034323

e-mail: mariefabuse@gmail.com

Le 21 avril 2016

OBJET : candidature au poste de récepionniste (monitrice)

Madame le Directeur,

Vous recherchez actuellement une monitrice, qui soit responsable et $d y$ namique, pour compléter votre équipe pendant la période des vacances de printemps. J'ai l'honneur de poser ma candidature, espérant mon premier stage à l'étranger.

Je suis vraiment passionnée par le métier exigeant de la sociabilité et le contact avec les gens, j'ai déjà eu une petite expérience de réceptionniste pendant ces dernières vacances d'été dans une banque dans ma ville.

Travailleuse et consciencieuse dans mon travail, je suis prête à effectuer le mieux possible toutes les responsabilités demandées.

J'espère par ma vive motivation pourrait attirer votre attention. Je suis à votre entière disposition pour tous les renseignements complémentaires.

Dans cette attente, je vous prie d'agréer, Madame le Directeur, l'expression de mes salutations distinguées.

\section{Marie Fabuse}

Переведем данное письмо на русский язык:

Мари Фабюз

Франция

175011 Бордо, ул. д’Этуаль, 31

тел.: 0132034323

e-mail: mariefabuse@gmail.com

21 апреля 2016 г.

TEMA: предложение кандидатуры на пост администратора (операmopa)

Уважаемая г-жа директор,

В настоящий момент Вы ищеme оператора, который обладал бы такими качествами, как ответственность и активность, и пополнил бы вашу команду на время весенних каникул. Осмелюсь предложить свою кандидатуру и полу- 
чить возможность впервые стажироваться за границей.

Я очень заинтересована в получении опыта на данной должности, требующей навыков общения с людьми, у меня уже имеется небольшой опыт работы администратором, который я получила во время последних летних каникул в банке нашего города.

Я трудолюба и добросовестно отношусь к работе, готова наилучшим образом выполнять все требуемые от меня обязанности.

Надеюсь, моя искренняя заинтересованность сможет привлечь Ваше внимание. Готова предоставить Вам любые дополнительные сведения.

жду Вашего ответа.

С уважением.

Мари Фабюз

При переводе данного письма особое внимание мы уделяем переводу фраз-клише и фрормул вежливости, которые играют большую роль в принятии решения адресатом. В письме на французском языке были использованы следующие фрразы-клише и формулы вежливости: Madame le Directeur; J'ai l'honneur de; je suis prête à effectuer le mieux possible toutes les responsabilités demandées; Je suis à votre entière disposition pour tous les renseignements complémentaires; Dans cette attente, je vous pris d'agréer, Madame le Directeur, l'expression de mes salutations distinguées.

Для того, чтобы перевод письма был адекватным и чтобы адресат воспринял его серьезно, необходимо подбирать правильные эквиваленты к фразам-клише и фрормулам вежливости. Таким образом, при переводе были использованы следующие виды клише:

- клише-кальки: je suis prête à effectuer le mieux possible toutes les responsabilités demandées - готова наилучшим образом выполнять все требуемые от меня обязанности;

- смысловые клише: Madame le Directeur - Уважаемая 2-жа дuректор; J'ai l'honneur de poser ma candidature... - Осмелюсь предложить свою кандидатуру...; Je suis vraiment passionnée... - Я очень заинтересована в...;

- ситуационные клише: Je suis à votre entière disposition pour tous les renseignements complémentaires. Готова предоставить Вам любые дополнительные сведения. Dans cette attente, je vous pris d'agréer, Madame le Directeur, l'expression de

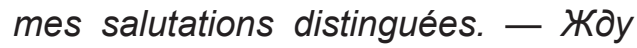
Вашего ответа. С уважением.

\section{Заключение}

Таким образом, в результате проведенного нами анализа можно сделать вывод, что при переводе деловых писем следует обращать особое внимание на лингвокультурологический аспект, который, главным образом, проявляется при переводе фраз-клише и фрормул вежливости. Так как данные фразы играют важную роль при составлении текста делового письма на любом языке, необходимо знать особенности их употребления как в языке оригинала, так и в языке перевода.

Проведя необходимый анализ текстов оригинала и перевода и переведя деловые письма с французского языка на русский, мы пришли к выводу, что, как правило, не стоит прибегать к употреблению клише-калек, то есть дословного перевода, 
так как в большинстве случаев данный перевод может вызвать недопонимание между адресатом и адресантом. Чаще стоит употреблять смысловые и ситуационные клише, которые позволяют максимально точно передать смысл текста, но при этом сделать текст перевода наиболее соответствующим нормам и культуре языка перевода.

Кроме того, нами было отмечено, что во французском деловом письме наблюдается большее количество формул вежливости и клишированной лексики, чем в русском, где, в свою очередь, также присутствуют формулы вежливости и клише, но в более простой форме, что придает письмам отличную друг от друга тональность, которую необходимо учитывать при переводе. Исходя из всего вышесказанного, следует отметить, что французское деловое письмо в большей степени направлено на соблюдение формул вежливости, и можно предположить, что во французском деловом письме формально адресат ставится выше адресанта, что отличает его от русского, в котором нарочито подчеркнутая вежливость может рассматриваться адресатом как насмешка.

\section{СПИСОК ИСПОЛЬЗОВАННОЙ ЛИТЕРАТУРЫ}

1. Язык, сознание, коммуникация : сб. научный статей / ред.: В. В. Красных, А. И. Изотов, В. Г. Кульпина. - М. : МАКС Пресс, 2009. - Вып. 39. - 136 с.

2. Маслова В. А. Лингвокультурология : учеб. пособие / В. А. Маслова. - М. : Академия, 2001. - 208 с.

3. Вежбицкая А. Язык. Культура. Познание / А. Вежбицкая. - М. : Русские словарь, 1996. - $416 \mathrm{c}$.

4. Иванова С. В. Лингвокультурология: проблемы, поиски, решения : монография / С. В. Иванова, 3. 3. Чанышева. - Уфра : РИЦ БашГУ, 2010. - 366 с.

5. Герасименко А. В. Межъязыковые лакуны в системе английского и русского существительного / А. В. Герасименко // Научное сообщество студентов XXI столетия. Гуманитарные науки : материалы XXVII студ. междунар. науч.-практ. конф. - Новосибирск, 2014. — № 12 (27). - С. 73-80.

6. Жеребило Т. В. Словарь лингвистических терминов / Т. В. Жебило. - Назрань : Пилигрим, 2010. - 486 с.

7. Граудина Л. К. Культура русской речи : учебник / Л. К. Граудина, Е. Н. Ширяев. М. : Норма-Инфра, 1999. - 560 с.

8. Балашова Л. В. Курс русского языка. Русский язык и культура общения / Л. В. Балашова, В. В. Дементьев. - Саратов : Лицей, 2005. - 1054 с.

9. Мешкова И. Н. Некоторые особенности официально-делового стиля французского языка в правовой сфере / И. Н. Мешкова // Вестник РУДН. Серия: Юридические науки. - 2013. - № 3. - С. 301-302.

10. Whittaker S. La correspondance commerciale: apprentissage de stratégies discursives en langue étrangère // Revue française de linguistique appliquée. 2001. — № 2. — P. 95-102.

11. Исмагилова Л. Р. Лексические особенности перевода деловой корреспонденции (на материале деловых писем на английском языке экономической направленности) / Л. Р. Исмаилова // Вестник Челябинского государственного университета. - 2012. № 21 (275). - С. 57-60.

12. Коняева Е. А. Особенности лексического состава деловой корреспонденции на русском и фрранцузском языках / Е. А. Коняева // Вестник РУДН. Серия: Теория языка. Семиотика. Семантика. - 2013. - № 4. - С. 102-107.

13. Рябцева Н. К. Прикладные проблемы переводоведения: Лингвистический аспект : учеб. пособие / Н. К. Рябцева. - М. : ФЛИНТА, 2014. — 224 с. 
14. Ожегов С. И. Толковый словарь русского языка / С. И. Ожегов, Н. Ю. Шведова. М., 2010. - 944 c.

15. Комиссаров В. Н. Теория перевода (лингвистические аспекты) : учебник / В. Н. Комиссаров. - М. : Высш. шк., 1990. - 253 с.

16. Темирбулатова А. К. Особенности перевода деловых документов (с английского языка на русский) [Электронный ресурс] / А. К. Темирбулатова, К. В. Бутенко // Студенческий научный фрорум-2015 : VII Международная студенческая электронная научная конференция. - Режим доступа: http://www.scienceforum.ru/2015/1086/10512.

17. Казанцев А. И. Особенности перевода клише и штампов официально-делового языка (на материале французского языка) : учебное пособие / А. И. Казанцев. - Челябинск, 2002. - 66 с.

18. Гак Г. В. Теория и практика перевода. Французский язык : учеб. пособие / Г. В. Гак, Б. Б. Григорьев. - Изд. 10-е. - М. : ЛИБРОКОМ, 2013. - 464 с.

\section{REFERENCES}

1. Krasnykh V. V., Izotov A. I., Kul'pina V. G. (eds). Yazyk, soznanie, kommunikatsiya [Language - Mind - Communication]. Moscow, MAKS Press Publ., 2009, vol. 39. 136 p.

2. Maslova V. A. Lingvokul'turologiya [Linguistic Culturology]. Moscow, Akademiya Publ., 2001. 208 p.

3. Vezhbitskaya A. Yazyk. Kul'tura. Poznanie [Semantics, Culture, and Cognition]. Moscow, Russkie slovar' Publ., 1996. 416 p.

4. Ivanova S. V., Chanysheva Z. Z. Lingvokul'turologiya: problemy, poiski, resheniya [Linguistic Culturology: Issues, Search, Solutions]. Ufa, Bashkirskii gosudarstvennyi universitet Publ., 2010. 366 p.

5. Gerasimenko A. V. Interlangauge lacunae in the system of English and rusisan nouns. Nauchnoe soobshchestvo studentov XXI stoletiya. Gumanitarnye nauki. Materialy 27 studencheskoi mezhdunarodnoi nauchno-prakticheskoi konferentsii [ $21^{\text {st }}$ century student scientific community. Humanities. Publications of the $18^{\text {th }}$ international student conference]. Novosibirsk, 2014, no. 12 (27), pp. 73-80. (In Russian).

6. Zherebilo T. V. Slovar' lingvisticheskikh terminov [Glossary of Linguistic Terms]. Nazran', Piligrim Publ., 2010. 486 p.

7. Graudina L. K., Shiryaev E. N. Kul'tura russkoi rechi [Culture of Spoken Russian]. Moscow, Norma-Infra Publ., 1999. 560 p.

8. Balashova L. V., Dement'ev V. V. Kurs russkogo yazyka. Russkii yazyk i kul'tura obshcheniya [A Course of Russian. The Russian language and Culture of Communication]. Saratov, Litsei Publ., 2005. 1054 p.

9. Meshkova I. N. Some features of official business style in the French language. Vestnik RUDN. Seriya: Yuridicheskie nauki = RUDN Journal of Law, 2013, no. 3, pp. 301-302. (In Russian).

10. Whittaker S. La correspondance commerciale: apprentissage de stratégies discursives en langue étrangère. Revue française de linguistique appliquée, 2001, no. 2, pp. 95102.

11. Ismagilova L. R. Lexical specifics of translating business correspondence (as exemplified by English business letters related to economy)). Vestnik Chelyabinskogo gosudarstvennogo universiteta = Bulletin of Chelyabinsk State University, 2012, no. 21 (275), pp. 57-60. (In Russian).

12. Konyaeva E. A. Features of Lexical Composition in Business Correspondence in Russian and French. Vestnik RUDN. Seriya: Teoriya yazyka. Semiotika. Semantika = RUDN Journal of Language Studies, Semiotics and Semantics, 2013, no. 4, pp. 102-107. (In Russian).

13. Ryabtseva N. K. Prikladnye problemy perevodovedeniya: Lingvisticheskii aspekt [Applied issues of translation: Linguistic aspect]. Moscow, FLINTA Publ., 2014. 224 p.

14. Ozhegov S. I., Shvedova N. Yu. Tolkovyi slovar' russkogo yazyka [Dictionary of the Russian language]. Moscow, 2010. 944 p. 
15. Komissarov V. N. Teoriya perevoda (lingvisticheskie aspekty) [Theory of translation (linguistic aspects)]. Moscow, Vysshaya shkola Publ., 1990. 253 p.

16. Temirbulatova A. K., Butenko K. V. How to translate business papers (from English into Russian). Studencheskii nauchnyi forum-2015. VII Mezhdunarodnaya studencheskaya elektronnaya nauchnaya konferentsiya [Student scientific forum of 2015. VII International student online conference]. Available at: http://www.scienceforum.ru/2015/1086/10512. (In Russian).

17. Kazantsev A. I. Osobennosti perevoda klishe i shtampov ofitsial'no-delovogo yazyka (na materiale frantsuzskogo yazyka) [How to translate business and formal clichés and hackneyed phrases from French]. Chelyabinsk, 2002. 66 p.

18. Gak G. V., Grigor'ev B. B. Teoriya i praktika perevoda. Frantsuzskii yazyk [Theory and Practice of Translation. The French language]. 10 ${ }^{\text {th }}$ ed. Moscow, LIBROKOM Publ., 2013. $464 \mathrm{p}$.

\section{для цитиРовния}

Нелюбова Н. Ю. Роль лингвокультурного фактора при переводе французской и русской деловой интернет-переписки / Н. Ю. Нелюбова, А. В. Гурова // Вопросы теории и практики журналистики. - 2018. - T. 7, № 1. - С. 100-113. DOI: 10.17150/23086203.2018.7(1).100-113.

\section{FOR CITATION}

Nelubova N. U., Gurova A. V. The Role of the Linguocultural Factor in Translation of French and Russian Online Business Correspondence. Voprosy teorii i praktiki zhurnalistiki = Theoretical and Practical Issues of Journalism, 2018, vol. 7, no. 1, pp. 100-113. DOI: 10.17150/2308-6203.2018.7(1).100-113. (In Russian). 